\title{
Deinagkistrodon acutus envenomation: a report of three cases
}

\author{
Chin-Lung Cheng ${ }^{1,2}$, Yan-Chiao Mao ${ }^{2,3,4}$, Po-Yu Liu', Liao-Chun Chiang ${ }^{6,7}$, Shu-Chen Liao ${ }^{4,8}$ \\ and Chen-Chang Yang ${ }^{3,4^{*}}$
}

\begin{abstract}
Background: Deinagkistrodon acutus envenomation is associated with severe hematological and wound complications but is rarely described.

Case presentation: Herein, we report three cases of victims bitten by D. acutus and indicate that rapid-onset severe coagulopathy and thrombocytopenia are distinct features of $D$. acutus snakebite, which are not observed in other crotaline snakebites (i.e., Trimeresurus stejnegeri and Protobothrops mucrosquamatus) in Taiwan. The toxic effects could occur as early as 2 to $3 \mathrm{~h}$ following $\mathrm{D}$. acutus envenomation and persist if the administration of specific antivenom is delayed or even not commenced. Based on our findings, 2 to 4 vials of specific antivenom as the first dose should be administered to victims and repeated at 6 to $8 \mathrm{~h}$ intervals if coagulopathy or thrombocytopenia persists. Fresh frozen plasma or platelet replacement is probably safe as an adjunct therapy for D. acutus bite in the presence of venominduced consumptive coagulopathy.
\end{abstract}

Conclusion: Severe coagulopathy and thrombocytopenia could occur as early as 2 to $3 \mathrm{~h}$ after D. acutus envenomation. The current recommendation for antivenom is 2 to 4 vials as the first dose and repeated every $6-$ to $8 \mathrm{~h}$ if coagulopathy or thrombocytopenia persists. These cases studied may be helpful to first-line medical personnel in the early diagnosis and management of D. acutus envenomation among other crotaline snakebites in Taiwan.

Keywords: Coagulopathy, Thrombocytopenia, Envenomation, Deinagkistrodon acutus, Snakebite

\section{Background}

Envenomation caused by snakebite comprises a worldwide public health problem, especially in Asia [1]. The venoms of snakes are a fascinating mix that allow the design of new drugs for use in medicine, as well as being a challenge for researchers in the development of specific antivenoms [2-5]. In Taiwan, six major venomous snakes are found, namely: Trimeresurus stejnegeri, Protobothrops mucrosquamatus, Deinagkistrodon acutus and Daboia siamensis in the family Viperidae, and Naja atra and Bungarus multicinctus in the family Elapidae [6]. D. acutus - also known as the hundred pacer, five pacer or Chinese moccasin - is the largest snake $(80-155 \mathrm{~cm})$ of the subfamily Crotalinae

\footnotetext{
* Correspondence: ccyang@vghtpe.gov.tw

${ }^{3}$ Department of Medicine, Division of Clinical Toxicology and Occupational Medicine, Taipei Veterans General Hospital, 201 Sec. 2, Shipai Road., Taipei 112, Taiwan

${ }^{4}$ Institute of Environmental and Occupational Health Sciences, School of Medicine, National Yang-Ming University, Taipei, Taiwan

Full list of author information is available at the end of the article
}

on the island [6]. It is additionally distributed throughout south China, Vietnam and possibly Laos [7]. D. acutus envenomation is rare; however, it is considered the most lethal and can result in life- or limb-threatening complications after envenomation $[6,8]$. Although severe coagulopathy and thrombocytopenia, defined as an international normalized ratio (INR) of prothrombin time (PT) $>9$ and platelet count $<50,000 / \mathrm{mm}^{3}$, are considered the hallmarks of $D$. acutus envenomation, little is known about the timing of onset and treatment with specific antivenom [9-13]. In the present study, we summarize the clinical manifestations and treatment of three cases of $D$. acutus envenomation admitted to Taichung Veterans General Hospital (VGH-TC) with the aim of improving the diagnosis and management of $D$. acutus envenomation.

\section{Case Presentation}

\section{Case 1}

A 36-year-old previously healthy man was bitten on his right hand by a snake during cleaning work around his 
home. He was immediately sent to a local hospital, with the dead snake identified as D. acutus. However, only two vials of antivenom for T. stejnegeri and P. mucrosquamatus were administered, because specific antivenom for $D$. acutus was not available and because the treating physician believed that cross-neutralization would occur. He received right upper limb fasciotomy on day 2 for suspected compartment syndrome. On day 3 , he was transferred to VGH-TC due to worsening of his general condition and bleeding tendency. On arrival, the patient's blood pressure (BP) was 109/47 $\mathrm{mmHg}$, pulse $119 / \mathrm{min}$, respiratory rate $20 / \mathrm{min}$, and body temperature $38.5^{\circ} \mathrm{C}$.

Physical examination revealed continuous oozing from the wound and venous catheter insertion site, multiple hemorrhagic bullae, swelling extending up to the shoulder and gross hematuria in the urinary bag. Laboratory examination revealed a hemoglobin level of $5.8 \mathrm{~g} / \mathrm{dL}$ (reference range 14-18 g/dL), platelet count $17,000 / \mathrm{mm}^{3}$ (reference range $150,000-400,000 / \mathrm{mm}^{3}$ ), fibrinogen $130 \mathrm{mg} / \mathrm{dL}$ (reference range $200-400 \mathrm{mg} / \mathrm{dL}$ ), D-dimer $>1 \mu \mathrm{g} / \mathrm{mL}$ (reference range $<0.55 \mu \mathrm{g} / \mathrm{mL}$ ), fibrinogen degradation products (FDPs) $>40 \mu \mathrm{g} / \mathrm{mL}$ (reference range $<10 \mu \mathrm{g} / \mathrm{mL}$ ), and incoagulable blood [PT $>169 \mathrm{~s}$; activated partial thromboplastin time $(\mathrm{aPTT})>224 \mathrm{~s}$ ] (Table 1 ).

Three vials of monovalent antivenom for $D$. acutus and blood components $[600 \mathrm{~mL}$ of packed red blood cells, $600 \mathrm{~mL}$ of fresh frozen plasma (FFP), and $300 \mathrm{~mL}$ of platelet concentrate] were immediately administered, resulting in a good response (Fig. 1). The patient's blood coagulation normalized at $6 \mathrm{~h}$ after administration of the antivenom and oozing from the wound stopped. A follow-up coagulation profile did not reveal recurrent coagulopathy on days 4, 10 and 13. He had intermittent fever, and extensive wound necrosis that required repetitive debridement on days 8,12 and 17 during hospitalization. Deep tissue cultures obtained during surgery grew Pseudomonas aeruginosa, Morganella morganii, Staphylococcus aureus and Enterococcus spp. Although thrombocytopenia persisted throughout days 4 to $10\left(22,000-116,000 / \mathrm{mm}^{3}\right)$, it was amenable to platelet transfusion and medical treatment. The bite wound improved gradually after antibiotic therapy and debridement. Staged wound closure was performed 3 weeks post-bite, and he was transferred to another hospital for a rehabilitation program 1 month later.

\section{Case 2}

A 41-year-old previously healthy woman was bitten on the left ankle by a snake while she collected herbs in northwestern Taiwan. She was sent to a local hospital $3 \mathrm{~h}$ later, where thrombocytopenia $\left(3000 / \mathrm{mm}^{3}\right)$ and incoagulable blood (PT $>100 \mathrm{~s}$ ) were noted. The snake was identified as $D$. acutus by the patient through a picture; however, two vials of antivenom for $T$. stejnegeri
Table 1 Initial blood laboratory data of the three patients at Taichung Veterans General Hospital

\begin{tabular}{|c|c|c|c|}
\hline Laboratory data (On arrival, day 1) & Case 1 & Case 2 & Case 3 \\
\hline $\begin{array}{l}\text { White blood cell count } \\
\left(4,500-11,000 / \mathrm{mm}^{3}\right)\end{array}$ & 4,700 & 12,300 & 9,300 \\
\hline \multicolumn{4}{|l|}{ Differential count (\%) } \\
\hline Neutrophil & 76.9 & 84.7 & 44 \\
\hline Lymphocyte & 15.2 & 7.6 & 45.2 \\
\hline $\begin{array}{l}\text { Hemoglobin (male: 14-18, } \\
\text { female } 12-16 \mathrm{~g} / \mathrm{dL} \text { ) }\end{array}$ & 5.8 & 13.1 & 15.4 \\
\hline $\begin{array}{l}\text { Platelet count } \\
\left(150,000-400,000 / \mathrm{mm}^{3}\right)\end{array}$ & 17,000 & 14,000 & 17,000 \\
\hline Sodium (mEq/L) & 136 & 142 & 144 \\
\hline Potassium (mEq/L) & 4.0 & 4.0 & 3.7 \\
\hline $\begin{array}{l}\text { Blood urea nitrogen } \\
(5-25 \mathrm{mg} / \mathrm{dL})\end{array}$ & 12 & 14 & 24 \\
\hline Creatinine $(0.7-1.4$ mg/dL) & 0.7 & 1.4 & 0.9 \\
\hline $\begin{array}{l}\text { Alanine aminotransferase } \\
\text { (male: } 10-50 \text {, female: } 10-35 \mathrm{U} / \mathrm{L} \text { ) }\end{array}$ & 28 & 26 & 21 \\
\hline $\begin{array}{l}\text { Aspartate aminotransferase } \\
(8-38 \mathrm{U} / \mathrm{L})\end{array}$ & 30 & 43 & 26 \\
\hline Total bilirubin (0.2-1.6 mg/dL) & 1.3 & 0.8 & - \\
\hline Direct bilirubin (0-0.3 mg/dL) & 0 & 0.2 & - \\
\hline $\begin{array}{l}\text { Lactate dehydrogenase } \\
(120-240 \mathrm{U} / \mathrm{L})\end{array}$ & 206 & 181 & 242 \\
\hline Creatine kinase (10-160 U/L) & 855 & 745 & 155 \\
\hline Prothrombin time (seconds) & $>169$ & $>164$ & $>164$ \\
\hline $\begin{array}{l}\text { Activated partial thromboplastin } \\
\text { time }(s)\end{array}$ & $>224$ & $>224$ & $>224$ \\
\hline Fibrinogen (200-400 mg/dL) & 130 & - & 149.1 \\
\hline D-dimer $(<0.55 \mu \mathrm{g} / \mathrm{mL})$ & $>1$ & - & - \\
\hline $\begin{array}{l}\text { Fibrinogen degradation products } \\
\text { (FDPs }<10 \mu \mathrm{g} / \mathrm{mL} \text { ) }\end{array}$ & $>40$ & - & $>40$ \\
\hline
\end{tabular}

and $P$. mucrosquamatus were administered for an unknown reason. She was then referred to VGH-TC $7.5 \mathrm{~h}$ post-bite.

On arrival, her BP was 172/94 $\mathrm{mmHg}$, pulse $108 / \mathrm{min}$, respiratory rate $20 / \mathrm{min}$, and body temperature $39.3{ }^{\circ} \mathrm{C}$. Physical examination revealed many hemorrhagic bullae scattered along the calf, continuous oozing from the fang marks, and painful swelling extending to the knee region. Laboratory examination disclosed thrombocytopenia $\left(14,000 / \mathrm{mm}^{3}\right)$ and PT of $>169 \mathrm{~s}$ and aPTT of $>224 \mathrm{~s}$. Four vials of monovalent antivenom for $D$. acutus and blood components $(200 \mathrm{~mL}$ of FFP and $300 \mathrm{~mL}$ of platelet concentrate) were administered at $8.5 \mathrm{~h}$ post-bite. Her coagulation profiles normalized at $15 \mathrm{~h}$ post-bite. On day 2 , her platelet count increased to $158,000 / \mathrm{mm}^{3}$. Due to prolonged aPTT (43.3-44.6 s), another seven vials of antivenom ( 2 to 3 vials every 6 to $8 \mathrm{~h}$ ) were sequentially administered without measurable responses. 


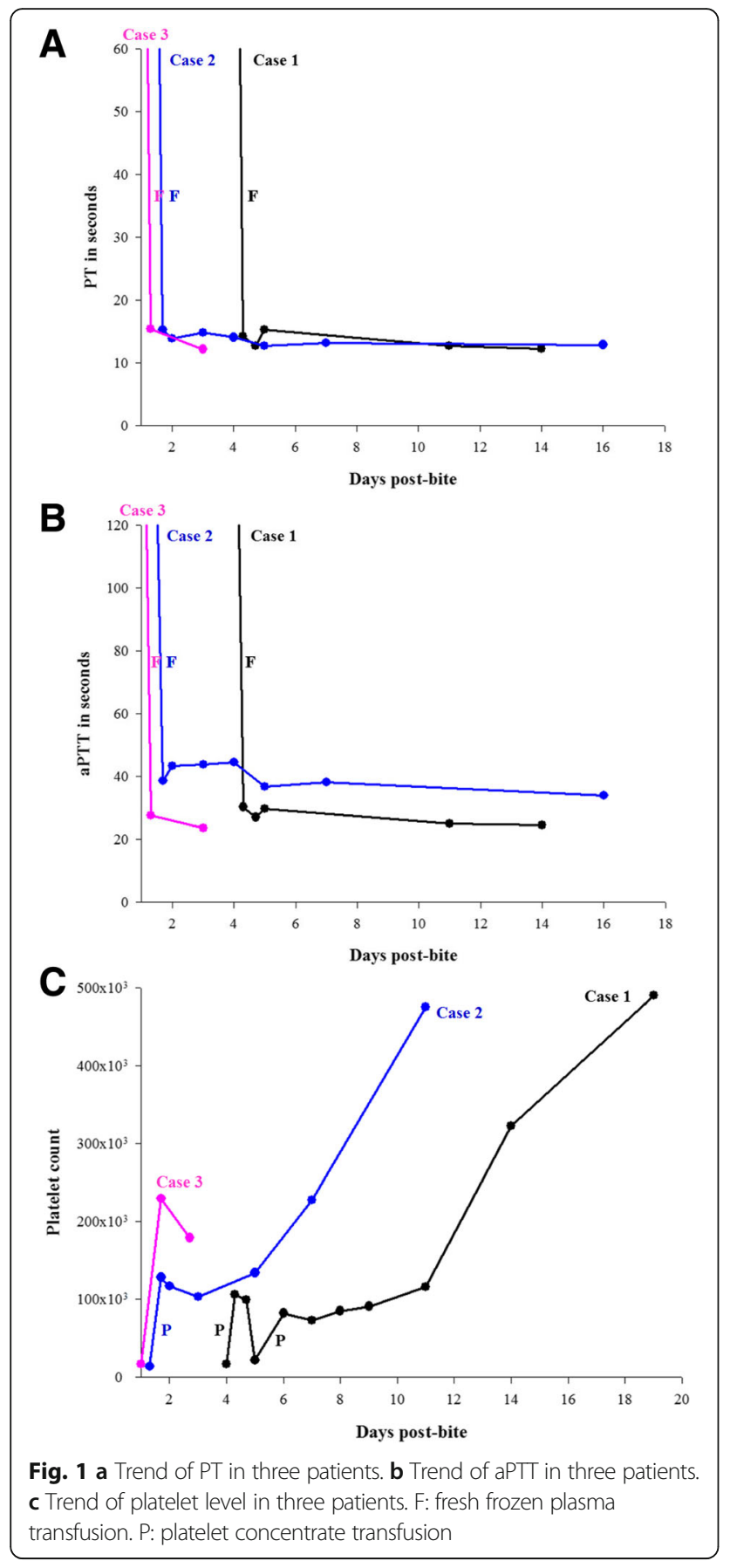

The leg wound was complicated with necrotizing fasciitis that required repetitive debridement on days 21 and 31 and supplemental hyperbaric oxygen therapy. The wound cultures obtained during surgery revealed S. aureus, Enterococcus spp. and Bacteroides fragilis. After antibiotic treatment, her wound infection improved and split-thickness skin grafting was performed after debridement on day 31 . The patient was discharged on day 47 post-bite with good functional recovery of the leg.

\section{Case 3}

A 69-year-old previously healthy woman was bitten on the left middle finger by a snake while collecting firewood. Painful swelling, tissue ecchymosis, and oozing from the wound developed a few minutes later. The patient was sent to VGH-TC $2 \mathrm{~h}$ post-bite. The dead snake brought in by the patient was identified as $D$. acutus. On arrival, her BP was 200/120 $\mathrm{mmHg}$, pulse $95 / \mathrm{min}$, respiratory rate $22 / \mathrm{min}$, and body temperature $36.7{ }^{\circ} \mathrm{C}$. Physical examination revealed swelling of left hand. A low platelet count $\left(17,000 / \mathrm{mm}^{3}\right), \mathrm{PT}>169 \mathrm{~s}, \mathrm{aPTT}>$ $224 \mathrm{~s}$, fibrinogen level $149.1 \mathrm{mg} / \mathrm{dL}$ and FDPs $>40 \mu \mathrm{g} /$ $\mathrm{mL}$ were noted in laboratory analyses.

Four vials of monovalent antivenom for D. acutus and $1000 \mathrm{~mL}$ of FFP were administered. Seven hours post-bite, both PT and aPTT normalized, and the platelet count increased to $230,000 / \mathrm{mm}^{3}$. Because of recurrent oozing from the wound, another four vials of antivenom (two at $12 \mathrm{~h}$ intervals) were administered without examination of PT and aPTT levels in the following $24 \mathrm{~h}$. Although the surgeon recommended partial finger amputation due to finger necrosis, the patient declined and insisted on being discharged against medical advice on day 5 . No recurrent coagulopathy was noted prior to discharge; however, the patient did not return for follow-up.

\section{Discussion}

T. stejnegeri and P. mucrosquamatus account for more than $70 \%$ of snakebite cases each year in Taiwan, which share similar clinical manifestations as well as the same treatment with bivalent specific antivenom $[6,8]$. Sporadic cases with INR above 1.67 and platelet counts of 36,000/ $\mathrm{mm}^{3}$ were reported in $P$. mucrosquamatus envenomation, and none manifested systemic bleeding $[11,14]$. In contrast, severe coagulopathy and thrombocytopenia are the main laboratory findings of $D$. acutus envenomation in addition to serious wound complications and systemic bleeding [11-13]. Valenta et al. [15] reported a victim of $D$. acutus bite who developed incoagulable blood between 1.5 and $7 \mathrm{~h}$ post-bite. Hung et al. [13] reported the case of a man with persistent thrombocytopenia $44 \mathrm{~h}$ after envenomation; his platelet level was normal $30 \mathrm{~min}$ post-bite. In our observation, rapid-onset and severe coagulopathy and thrombocytopenia developed as early as 2 to $3 \mathrm{~h}$ postbite may persist if correct antivenom is not administered.

D. acutus venom is composed of several hemotoxins, including the thrombin-like enzymes (TLEs), anticoagulant toxins, platelet aggregation inhibitors, hemorrhagins, and enzymes that facilitate venom spreading [16-19]. The anticoagulation effect of TLEs occurs rapidly, and circulating fibrinogen levels start to fall within $30 \mathrm{~min}$, reaching $9 \%$ of the normal value within $2 \mathrm{~h}$ [16]. Anticoagulant toxins inactivate prothrombin, tissue factor and coagulation factors $\mathrm{V}$ and IX/X, resulting in a transient but marked 
prolongation of blood coagulation within 5 min after injection $[16,20,21]$. The platelet inhibitors, mainly adenosine diphosphatase, inhibit platelet aggregation in the presence of adenosine diphosphate or collagen [17]. The hemorrhagins (e.g., snake venom metalloproteinases) cause extensive vascular damage and increase vascular permeability [22]. These effects may explain the remarkable bleeding tendency and wound complications in $D$. acutus envenomation.

The Taiwan government produces four types of antivenom against the six major venomous snakebites [8]. Concerning the monovalent antivenom for $D$. acutus, each vial roughly neutralizes $52 \mathrm{mg}$ of venom. The Taiwan Poison Control Center thus recommends that 2 to 4 vials of antivenom be administered in a envenomed patient because the mean amount of $D$. acutus venom injected is $105.1 \mathrm{mg}$ [8]. However, this recommendation was not validated and there is no standard dosing regimen available in Taiwan. According to our findings, the current recommendation is 2 to 4 vials of antivenom to be administered as the first dose and repeated at 6 to $8 \mathrm{~h}$ intervals if coagulopathy or thrombocytopenia persists (e.g., INR $>3$, aPTT $>50$ s, and platelet level $\left.<20,000 / \mathrm{mm}^{3}\right)$ [23, 24]. Although crossneutralization occurs between bivalent antivenom for $T$. stejnegeri and $P$. mucrosquamatus and monovalent antivenom for $D$. acutus, substitution should be avoided as the bivalent antivenom has only a weak cross-reactivity with the $D$. acutus venom [13].

All of our cases had a rapid improvement in coagulopathy after receiving specific antivenom. In case 2 , $\mathrm{s}$ slightly prolonged aPTT persisted for 4 days without clinical thrombosis or bleeding tendency. Although a workup for prolonged aPTT was not performed in the case, it was probably unrelated to the venom because no apparent response was observed after repetitive antivenom administration [25]. In case 1 , thrombocytopenia did not show improvement after antivenom therapy, which was probably attributable to uncontrolled infection. Nevertheless, Valenta et al. [15] reported a single case of $D$. acutus envenomation who manifested severe coagulopathy in the absence of thrombocytopenia. Therefore, the exact mechanism of thrombocytopenia in D. acutus snakebite remains unclear.

Evidence suggests that, when compared with antivenom alone, early FFP replacement therapy shortens coagulopathy in patients suffering from hemotoxic snake envenomation and, theoretically, lower the risk of major bleeding [26]. The bleeding risk may be pronounced in cases of severe thrombocytopenia [10]. However, in cases of venom-induced thrombotic microangiopathy, platelet transfusion may be problematic [27]. In our study, no elevation of blood bilirubin or lactate dehydrogenase was found, and the first two cases had received platelet concentrate transfusions, resulting in good responses. It appears to be safe to use the blood component therapy during $D$. acutus envenomation. In case 3 , the platelet count spontaneously normalized after $24 \mathrm{~h}$ with FFP and specific antivenom administration alone. This effect may have occurred because of the relatively modest injury in this case. However, the patient received a higher dosage (eight vials) of antivenom, which was sufficient to counteract the venom effects on platelets.

\section{Conclusion}

Severe coagulopathy and thrombocytopenia could occur as early as 2 to $3 \mathrm{~h}$ after $D$. acutus envenomation. The current recommendation for antivenom therapy is 2 to 4 vials as the first dose and repeat it every 6 to $8 \mathrm{~h}$ if coagulopathy or thrombocytopenia persists. Our observation may be helpful to first-line medical personnel in the timely diagnosis and management of $D$. acutus bites.

\section{Abbreviations \\ aPTT: activated partial thromboplastin time; BP: Blood pressure; FDPs: Fibrinogen degradation products; FFP: Fresh frozen plasma; INR: International normalized ratio; PT: Prothrombin time; TLEs: Thrombin-like enzymes; VGH-TC: Taichung Veterans General Hospital}

\section{Acknowledgments}

Not applicable.

\section{Publisher's Note}

Springer Nature remains neutral with regard to jurisdictional claims in published maps and institutional affiliations.

\section{Funding}

Not applicable.

\section{Authors' contributions}

The first two authors, CLC and YCM interpreted the clinical findings and drafted the manuscript. The third to the fifth authors, PYL, LCC, and SCL provided professional opinions in bacteriology of snakebite and snake venomics and antivenomics, and revised the manuscript. The correspondent author CCY designed this study, interpreted the clinical findings and revised the manuscript. All authors read and approved the final manuscript.

\section{Competing interests}

The authors declare that they have no competing interests.

\section{Consent for publication}

Written informed consent was obtained from the patients for publication of this case report.

\section{Ethics approval and consent to participate}

The study protocol was approved by the Institutional Review Board of Taichung Veterans General Hospital (IRB, CE14202A).

\footnotetext{
Author details

'Department of Emergency Medicine, Kaohsiung Armed Forces General Hospital, Taipei, Taiwan. ${ }^{2}$ Department of Emergency Medicine, Division of Clinical Toxicology, Taichung Veterans General Hospital, Taipei, Taiwan. ${ }^{3}$ Department of Medicine, Division of Clinical Toxicology and Occupational Medicine, Taipei Veterans General Hospital, 201 Sec. 2, Shipai Road., Taipei 112, Taiwan. ${ }^{4}$ Institute of Environmental and Occupational Health Sciences, School of Medicine, National Yang-Ming University, Taipei, Taiwan.

${ }^{5}$ Department of Medicine, Division of Infection, Taichung Veterans General Hospital, Taichung, Taiwan. ${ }^{6}$ National Tsing Hua University, College of Life Sciences, Hsinchu, Taiwan. ${ }^{7}$ National Health Research Institutes, National Institute of Infectious Diseases and Vaccinology, Zhunan, Miaoli, Taiwan.
} 
${ }^{8}$ Department of Emergency Medicine, Chang Guang Memorial Hospital, Taipei, Taiwan.

Received: 30 September 2016 Accepted: 21 March 2017 Published online: 23 March 2017

\section{References}

1. World Health Organization (WHO). Snake antivenoms. Fact sheet $N^{\circ} 337$ Reviewed February 2015. Retrieved from http://www.who.int/mediacentre/ factsheets/fs337/en/. Accessed 23 Oct 2016

2. Wei CB, Chen J, Li JH. Acutolysin C, a weak hemorrhagic toxin from the venom of Agkistrodon acutus with leucoagglutination activity. J Venom Anim Toxins incl Trop Dis. 2011:17(1):34-41.

3. Wei $C B$, Chen J. A novel lipocalin homologue from the venom gland of Deinagkistrodon acutus similar to mammalian lipocalins. J Venom Anim Toxins incl Trop Dis. 2012;18(1):16-23.

4. Chieh-Fan C, Tzeng-Jih L, Wen-Chi H, Hua-Wei Y. Appropriate antivenom doses for six types of envenomations caused by snakes in Taiwan. J Venom Anim Toxins incl Trop Dis. 2009;15(3):479-90.

5. Ratanabanangkoon $\mathrm{K}$, Tan KY, Eursakun $\mathrm{S}$, Tan $\mathrm{CH}$, Simsiriwong $\mathrm{P}$, Pamornsakda T, et al. A simple and novel strategy for the production of a pan-specific antiserum against elapid snakes of Asia. PLoS Negl Trop Dis. 2016;10(4):e0004565

6. Mao YC, Hung DZ. Epidemiology of snake envenomation in Taiwan. Clinical Toxinology in Asia Pacific and Africa. 2015. p. 3-22. http://link.springer.com/ referenceworkentry/10.1007/978-94-007-6386-9 45. Accessed 21 Feb 2017

7. Uetz P, Hošek J. The Reptile Database. Retrieved from http://www.reptiledatabase.org/. Accessed 8 Dec 2014

8. Mao YC, Hung DZ. Management of snake envenomation in Taiwan. Clinical Toxinology in Asia Pacific and Africa. 2015. p. 23-52. http://link.springer. com/referenceworkentry/10.1007/978-94-007-6386-9_43. Accessed 21 Feb 2017.

9. Ansell J, Hirsh J, Hylek E, Jacobson A, Crowther M, Palareti G, et al. Pharmacology and management of the vitamin K antagonists: American College of Chest Physicians evidence-based clinical practice guidelines. Chest. 2008;133(6_Suppl):160S-98.

10. Williamson DR, Albert M, Heels-Ansdell D, Arnold DM, Lauzier F, Zarychanski R, et al. Thrombocytopenia in critically ill patients receiving thromboprophylaxis: frequency, risk factors, and outcomes. Chest. 2013;144(4):1207-15.

11. Shen MC. Afibrinogenemia and thrombocytopenia following crotalid snake bites in Taiwan. J Formos Med Assoc. 1983;82(2):239-44.

12. Rao DS. Clinical observation of 21 cases of Agkistrodon acutus (Guenther) bite complicated by disseminated intravascular coagulation (author's transl). Zhonghua Nei Ke Za Zhi. 1981:20(11):670-2.

13. Hung DZ, Wu TC, Deng JF. The painful experience of inappropriate therapy of snake bites: a report of two cases. Zhonghua Yi Xue Za Zhi (Taipei). 1997; 60(6):326-30.

14. Chen YW, Chen MH, Chen YC, Hung DZ, Chen CK, Yen DHT, et al. Differences in clinical profiles of patients with Protobothrops mucrosquamatus and Viridovipera stejnegeri envenoming in Taiwan. Am J Trop Med Hyg. 2009:80(1):28-32.

15. Valenta J, Stach Z, Michalek P. Envenoming by Crotalid Snake Chinese Moccasin Agkistrodon Acutus Bite - A Case Report. Prague Med Rep. 2015; 116(2):155-60.

16. Ouyang C, Teng CM. In vivo effects of the purified thrombin-like and anticoagulant principles of Agkistrodon acutus (Hundred pace snake) venom. Toxicon. 1978;16(6):583-93.

17. Ouyang C, Huang TF. Platelet aggregation inhibitors from Agkistrodon acutus snake venom. Toxicon. 1986;24(11-12):1099-106.

18. Xu X, Wang C, Liu J, Lu Z. Purification and characterization of hemorrhagic components from Agkistrodon acutus (hundred pace snake) venom. Toxicon. 1981;19(5):633-44

19. Xu X, Wang XS, Xi XT, Liu J, Huang JT, Lu ZX. Purification and partial characterization of hyaluronidase from five pace snake (Agkistrodon acutus) venom. Toxicon. 1982;20(6):973-81.

20. Ouyang $\mathrm{C}$, Teng $\mathrm{CM}$. The effect of the purified anticoagulant principle of Agkistrodon acutus venom on blood coagulation. Toxicon. 1973;11(3):287-92.

21. Ouyang C, Teng CM, Huang TF. Characterization of the purified principles of Formosan snake venoms which affect blood coagulation and platelet aggregation. J Formos Med Assoc. 1982;81(7):781-90.

22. Kamiguti AS. Platelets as targets of snake venom metalloproteinases. Toxicon. 2005;45(8):1041-9.
23. Gold BS, Dart RC, Barish RA. Bites of venomous snakes. N Engl J Med. 2002; 347(5):347-56.

24. Boyer LV, Seifert SA, Cain JS. Recurrence phenomena after immunoglobulin therapy for snake envenomations: Part 2. Guidelines for clinical management with crotaline Fab antivenom. Ann Emerg Med. 2001;37(2):196-201.

25. Chng WJ, Sum C, Kuperan P. Causes of isolated prolonged activated partial thromboplastin time in an acute care general hospital. Singapore Med J. 2005;46(9):450-6.

26. Isbister GK, Buckley NA, Page CB, Scorgie FE, Lincz LF, Seldon M, et al. A randomized controlled trial of fresh frozen plasma for treating venom-induced consumption coagulopathy in cases of Australian snakebite (ASP-18). J Thromb Haemost. 2013;11(7):1310-8.

27. Isbister GK. Snakebite doesn't cause disseminated intravascular coagulation: coagulopathy and thrombotic microangiopathy in snake envenoming. Semin Thromb Hemost. 2010;36(4):444-51.

\section{Submit your next manuscript to BioMed Central and we will help you at every step:}

- We accept pre-submission inquiries

- Our selector tool helps you to find the most relevant journal

- We provide round the clock customer support

- Convenient online submission

- Thorough peer review

- Inclusion in PubMed and all major indexing services

- Maximum visibility for your research

Submit your manuscript at www.biomedcentral.com/submit
Biomed Central 